\title{
Post Processing Methods used to Improve Surface Finish of Products which are Manufactured by Additive Manufacturing Technologies: A Review
}

\author{
N. N. Kumbhar ${ }^{1}$ A. V. Mulay ${ }^{1}$
}

Received: 31 August 2015/Accepted: 16 August 2016/Published online: 30 August 2016

(C) The Institution of Engineers (India) 2016

\begin{abstract}
The Additive Manufacturing (AM) processes open the possibility to go directly from Computer-Aided Design (CAD) to a physical prototype. These prototypes are used as test models before it is finalized as well as sometimes as a final product. Additive Manufacturing has many advantages over the traditional process used to develop a product such as allowing early customer involvement in product development, complex shape generation and also save time as well as money. Additive manufacturing also possess some special challenges that are usually worth overcoming such as Poor Surface quality, Physical Properties and use of specific raw material for manufacturing. To improve the surface quality several attempts had been made by controlling various process parameters of Additive manufacturing and also applying different post processing techniques on components manufactured by Additive manufacturing. The main objective of this work is to document an extensive literature review in the general area of post processing techniques which are used in Additive manufacturing.
\end{abstract}

Keywords Additive manufacturing .

Post processing technique $\cdot$ Surface finish .

Laser surface finishing

N. N. Kumbhar

kumbharnn88@gmail.com

1 Department of Production Engineering, College of Engineering, Pune 411005, India

\section{Introduction}

Additive manufacturing was born as a rapid prototyping technology with the process of joining materials in successive layer by layer to make objects. It allows designers to produce accurate physical prototypes directly from 3DCAD model in few hours.

The processes are best suited to parts which are generally complex in design with freeform curves and features, possessing only a limited percentage of plane surfaces. However, a major problem to commercial use is the poor surface finish caused by "Stair Casing Effect", which is shown in Fig. 1d [1].

Figure 1 gives idea about manufacturing steps in AM. Steps are listed below,

1. Generation of 3D CAD model by any commercial CAD software (Fig. 1a).

2. Slicing of a 3D CAD model in 2D layers (Fig. 1b).

3. Generation of physical output by stacking those $2 \mathrm{D}$ layers one by one (Fig. 1c).

Due to stacking of 2D layers the generated model having with poor surface finish because of the "Stair Casing Effect" shown in Fig. 1d.

To minimize the Stair casing effect several researchers worked on different process parameters related with Additive manufacturing such as part orientation, layer thickness and orientation of material deposition as well as to get the best results many researchers worked on different post-processing techniques.

There are different types of post processing techniques, which are used to improve surface quality depending upon the application and the model material. 
Fig. 1 An illustration of the layer-based additive manufacturing processes and related stair-stepping effect. a CAD Model, b Slicing c Actual output by AM d Stair casing effect

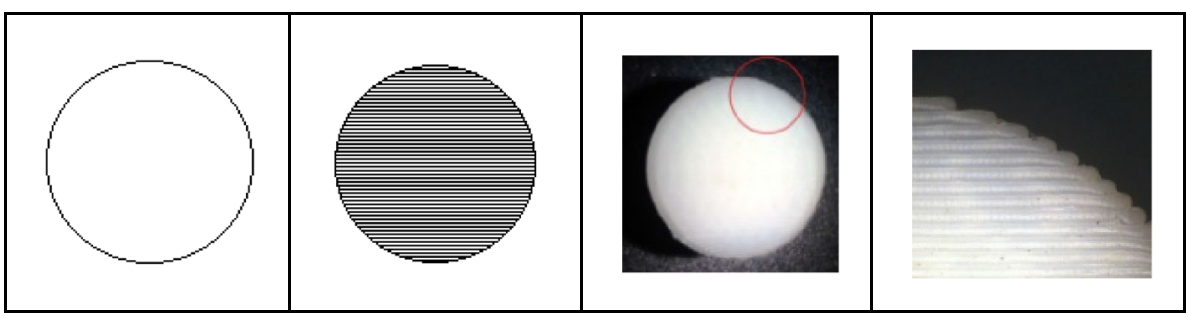

Table 1 Classification based on raw material used

\begin{tabular}{ll}
\hline Raw material used & Additive manufacturing process \\
\hline Polymer & Stereolithography (SLA) \\
& Fused Deposition Modeling (FDM) \\
& Three-dimensional Printing (3DP) \\
& Selective Laser Sintering (SLS) \\
& Laminated-Object Manufacturing (LOM) \\
& FDM \\
Metal & 3DP \\
& SLS \\
& Direct Metal Laser Sintering (DMLS) \\
Ceramic & 3DP \\
& SLS \\
\hline
\end{tabular}

\section{Additive Manufacturing Methods}

There are many different Additive manufacturing processes, all with their specific benefits, drawbacks and application areas. The available Additive manufacturing processes are classified on the bases of various characteristics such as type of raw material used, form of raw material and principle used [1].

The classification based on raw materials carried out is given in Table 1 and 2.

\section{Classification Based on Principle Used}

In 2010, the American Society for Testing and Materials (ASTM) group "ASTM F42-Additive Manufacturing" formulated a set of standards that classify the range of Additive Manufacturing processes into seven categories (Standard Terminology for Additive Manufacturing Technologies, 2012) [2]

1. VAT Photopolymerisation

2. Material Jetting

3. Binder Jetting

4. Material Extrusion

5. Powder Bed Fusion

6. Sheet Lamination

7. Directed Energy Deposition.
Table 3 shows various principles used for different types of Additive manufacturing processes.

These methods are having some capabilities such as,

- Unbounded geometric freedom,

- To control the local geometric (micro-structure)

- Avoid the use of tooling

- Lowered inventory requirements

- Waste-less fabrication

- Unattended operation (allowed fully automated operation)

- Customer-driven design.

As there are many advantages of AM, however there are some disadvantages also such as,

- Demand for better materials.

- Existing CAD systems.

- Data management (Size of STL file)

- Low-volume production

- Financial overheads

- Surface Quality of Products

Compared with other conventional AM method having low surface quality because of layer by layer manufacturing and stair casing effect on surface. As a result, the surface finish of the parts is not satisfactory and hence surface roughness is a key issue in AM. The different AM processes have yielded varying surface roughness results with respect to their layer thickness. The researchers have [3] investigated surface roughness values of parts which are generated by different AM processes. Table 4 below shows roughness values for different AM processes. As compared to other processes FDM gives a poor surface finish band $(9-40 \mu \mathrm{m})$.

To obtain the required surface finish several attempts have been made by optimizing process parameters such as part orientation, built orientation, layer thickness and using post processing operation such as machining operation (turning, milling, CNC machining), abrasive machining, chemical machining, laser surface finishing operations and abrasive flow machining. As there is much more work is carried on optimizing the process parameters such as 
Table 2 Classification based on form of raw material used

\begin{tabular}{lll}
\hline Supply phase & Additive manufacturing process & Materials \\
\hline Liquid & SLA & Photopolymers (acrylates, epoxies, colorable resins, filled resins) \\
& FDM & Polymers (ABS, polyacrylate, etc.), wax, metals and ceramics with binder \\
Powder & 3DP & Ceramic, polymer and metal powders with binder \\
& DMLS & \\
Solid & SLS & Polymers, metals with binder, metals, ceramics and sand with binder \\
& LOM & Paper, polymers \\
\hline
\end{tabular}

Table 3 Classification based on principle used

\begin{tabular}{ll}
\hline Principle used & Additive manufacturing process \\
\hline VAT photopolymerisation & - \\
Material jetting & Drop on Demand (DOD) \\
Binder jetting & - \\
Material extrusion & FDM \\
Powder bed fusion & DMLS \\
& Electron Beam Melting (EBM) \\
& Selective Heat Sintering (SHS) \\
& Selective Laser Melting (SLM) \\
& SLS \\
Sheet lamination & 3 DP \\
Directed energy deposition & LOM \\
\hline
\end{tabular}

Table 4 Surface roughness of AM technique [3]

\begin{tabular}{llll}
\hline $\begin{array}{l}\text { Sl. } \\
\text { no. }\end{array}$ & $\begin{array}{l}\text { Name of } \\
\text { process }\end{array}$ & $\begin{array}{l}\text { Minimum layer } \\
\text { thickness, mm }\end{array}$ & $\begin{array}{l}\text { Surface roughness } \\
(\mathrm{Ra}), \mu \mathrm{m}\end{array}$ \\
\hline 1 & SLA & 0.10 & $2-40$ \\
2 & SLS & 0.125 & $5-35$ \\
3 & FDM & 0.254 & $9-40$ \\
4 & 3D printing & 0.175 & $12-27$ \\
& (3DP) & & $6-27$ \\
5 & LOM & 0.114 & $3-30$ \\
6 & $\begin{array}{c}\text { Poly jetting } \\
\text { process }\end{array}$ & 0.10 & \\
\hline
\end{tabular}

controlling the part orientation at initial stage by different combinations with respect to STL file to get required output. Controlling the built orientation of parts in machine and controlling the layer thickness.

As discussed earlier, the "Stair Casing Effect", which is non-removable by parameter optimization. It has to be minimized by post-processing operation.

\section{Post Processing Techniques}

Additive manufacturing technique helps to develop a product from the basic design of the component and to optimize the iterative product development time. Although AM provides many advantages over other manufacturing technologies, it still has some major drawbacks such as the staircase effect, surface quality and dimensional accuracy. Most of the researchers worked on various post processing techniques to overcome the drawbacks.

Some of the researchers have [4] investigated two automated finishing techniques which are, Vibratory Bowl Abrasion Finishing and Ultrasonic Abrasion Finishing. By using these techniques, the experiments are carried out on components made from Ciba-Geigy XB5081-1 (durable resin) and XB 5143 (general purpose resin) resins with the aim of producing an acceptable surface roughness. After experimentation results from Scanning Electron Microscopy (SEM) and surface topography analyses suggested that both techniques are capable of improving the model surfaces. Compared with Ultrasonic abrasion finishing, Vibratory Bowl abrasion finishing process has achieved a good surface finish in a reasonable amount of time with improvements of around $74 \%$ (Initial $R_{\mathrm{a}}$ value is $5.71 \mu \mathrm{m}$-after processing $1.68 \mu \mathrm{m}$ ).

The investigators have [5] worked on vibratory grinding, which is used to refine SLS parts from the surfaces. In this method, the suitable ceramic bodies were investigated and process times were determined. By using optical variance analysis researcher were demonstrated that parts without complex structures are readily amenable to vibratory grinding (removal $<0.1 \mathrm{~mm}$ ) and the $R_{\mathrm{a}}$ value of surface is changed from 11 to $2 \mu \mathrm{m}$.

Some of the researchers have [6] conducted the experiments on parts built by FDM process using HCM (Hot Cutter Machining) processes is successfully attempt for enhancing surface finish. This machining process provides a layer by layer machining and it is observed that surface roughness is in the order of $0.3 \mu \mathrm{m}$ with $87 \%$ confidence level. But this method is restricted up to flat surfaces.

The investigators have $[7,8]$ studied the influence of a chemical post-processing treatment on FDM models which are manufactured from Acrylonitrile Butadiene Styrene (ABS) plastic. The experiment is carried out in chemical bath with dimethylketone (acetone), ester and chloride solvents. Dimethylketone was chosen due to its low cost, 
very low toxicity and very high diffusion rate. At the time of experimentation model is immersed in a volume of $90 \%$ dimethylketone and $10 \%$ water for $300 \mathrm{Sec}$. The model has been analysed and yields a significant improvement of the $R_{\mathrm{a}}$ value. The chemical post treatment does not require human intervention and has led to a significant improvement in surface finish at the expense of a negligible change in the prototype size. After post-processing $R_{\mathrm{a}}$ value varies in between 2-4 $\mu \mathrm{m}$.

The researchers have [9] discussed various methods which are used to improve the surface roughness of the parts which are generated by DMLS. DMLS gives a raw finish on model surface compare to a medium turned surface with a surface roughness of approximately $R_{\mathrm{a}}$ as $8.75 \mu \mathrm{m}$. This surface roughness can be improved all the way up to $R_{\mathrm{a}} 0.025 \mu \mathrm{m}$, qualifying as a super mirror finish. There are several processes available that can be used to achieve the desired surface roughness or finish of DMLS built models which are Abrasive Blast (Grit and Ceramic), Shot Peen, Polishing, Electrochemical Polishing, Optical Polish (Hand Finishing), CNC Finishing/Machining, Abrasive Flow Machining (Extrude Hone) Polishing, Electroplating, Micro Machining Process (MMP).

The investigators have [10] worked on a simple post processing method for improving surface quality of parts generated from AM. In this case study, aluminium filled epoxy resin is used as a filler to improve the surface quality of model fabricated by fused FDM. The average surface roughness of wax pattern can be drastically reduced from 17.10 to $2.76 \mu \mathrm{m}$. Surface roughness improvement up to $83.85 \%$ can be achieved.

Some researchers have [11] carried out the experiments on SLS built parts to improve surface finish by using $\mathrm{CO}_{2}$ and Nd:YAG lasers. On the basis of experiments, researchers observed that partial-melting of surface with an increase in $R_{\mathrm{a}}$ values and decrease in over-melting. The results obtained indicate that a reduction in $R_{\mathrm{a}}$ roughness has been achieved in 420 stainless steel-bronze infiltrated SLS parts by means of $\mathrm{CO}_{2}$ and Nd: YAG laser polishing. The best results are: (1) $R_{\mathrm{a}}$ reduction from 2.1 to $1.6 \mu \mathrm{m}$ at $220 \mathrm{~W}$ and $2.2 \mathrm{~mm} / \mathrm{s}$ (2) $R_{\mathrm{a}}$ reduction from 2.38 to $1.65 \mu \mathrm{m}$ at $320 \mathrm{~W}$ and $1.19 \mathrm{~mm} / \mathrm{s}$ and (3) $R_{\mathrm{a}}$ reduction from 2.38 to $0.8 \mu \mathrm{m}$ at $420 \mathrm{~W}$ and $4.5 \mathrm{~mm} / \mathrm{s}$. By means of $\mathrm{Nd}$ : YAG laser polishing the best result is a $R_{\mathrm{a}}$ reduction from 9.0 to $2.40 \mu \mathrm{m}$ at $220 \mathrm{~W}$ and $1.7 \mathrm{~mm} / \mathrm{s}$.

The researchers have [12] performed experiments on Laser-polishing tests for lines, planar surfaces and inclined planes. The experimental tests were carried out on the parts which are generated from the SLS process with an initial roughness of 7.5-7.8 $\mu \mathrm{m} \mathrm{Ra}$. After conducting Experimental results present final surface roughness below $1.49 \mu \mathrm{m} \mathrm{Ra}$, which represent an $80.1 \%$ reduction of the mean roughness.
Table 5 Post processing methods with respect to nature

\begin{tabular}{|c|c|}
\hline Conventional & Non-conventional \\
\hline $\begin{array}{l}\text { a. Vibratory bowl abrasion/abrasive blast } \\
\text { (grit and ceramic)/shot peen vibratory } \\
\text { grinding }\end{array}$ & $\begin{array}{l}\text { a. Ultrasonic abrasion } \\
\text { b. Chemical post- } \\
\text { processing treatment }\end{array}$ \\
\hline $\begin{array}{l}\text { b. HCM (hot cutter machining) } \\
\text { c. Optical polish (Hand finishing) }\end{array}$ & $\begin{array}{l}\text { c. Electrochemical } \\
\text { polishing, }\end{array}$ \\
\hline d. CNC Finishing/machining & d. Electroplating \\
\hline e. Micro machining process (MMP) & e. Laser micro \\
\hline $\begin{array}{l}\text { f. Filling the gaps by epoxy resin/part } \\
\text { painting }\end{array}$ & machining \\
\hline
\end{tabular}

Table 6 Post processing methods with respect to raw material

\begin{tabular}{ll}
\hline Raw material used & Post processing method \\
\hline Polymer & Vibratory bowl abrasion \\
& Hot Cutter Machining (HCM) \\
& Optical polish (Hand Finishing) \\
& Micro Machining Process (MMP) \\
& Filling the gaps by epoxy resin/Part painting \\
& Chemical post-processing treatment \\
& Electroplating \\
& Laser micro machining \\
& Vibratory bowl abrasion \\
& HCM (Hot cutter machining) \\
& Optical polish (hand finishing) \\
Metal & MMP \\
& Chemical post-processing treatment \\
& Electroplating \\
& Laser micro machining \\
& Vibratory bowl abrasion \\
& Optical polish (hand finishing) \\
MMP & Laser micro machining \\
\hline Ceramic & \\
&
\end{tabular}

It has been found that the surface finish can also be improved by using post processing techniques. Various post processing techniques are listed below in Table 5 on the bases of conventional and non-conventional approaches.

Also the same methods are categorized on the bases of raw material used in Additive manufacturing in Table 6.

Looking at Table 6, laser micromachining is common technique used as post processing operation on polymer, Metal and Ceramic. Therefore, this work is focused on laser surface finishing.

\section{Laser Surface Finishing}

The quality attributes of LASER combined with a high degree of flexibility, contact-less machining and the 


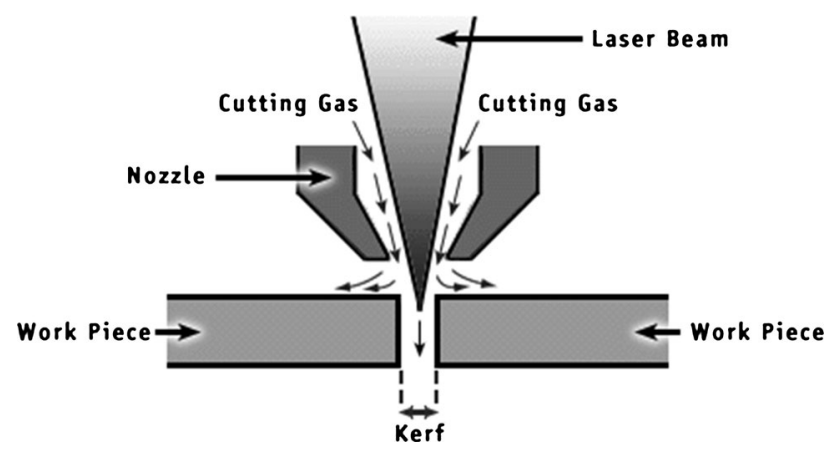

Fig. 2 Laser cutting operation

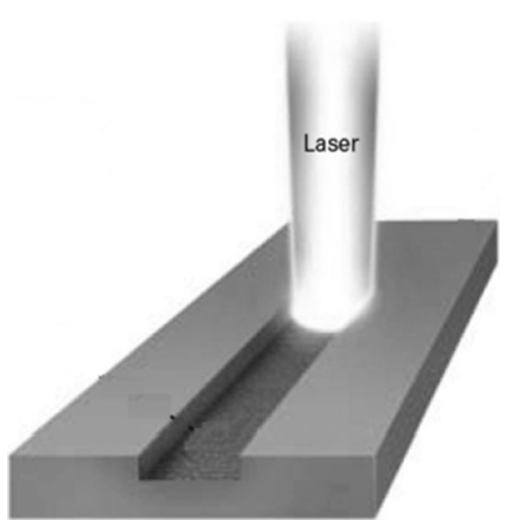

Fig. 3 Laser ablation process

possibility of high automation as well as easy integration allows us to use this tool in a wide field of macro machining processes on many materials including silicon, ceramics, metal and polymer.

The researchers have $[13,14]$ utilised laser micromachining that includes a number of different processes which are differentiated on the bases of feature geometry and the manner in which material is removed from the surface. In laser micromachining a beam is used to slice the substrate material, leaving behind a kerf which extends completely through to the opposite side of the substrate. As is commonly the case in laser cutting of sheet metal, the material removed from the kerf is predominantly ejected out the opposite side. Figure 2 Shows laser cutting operation.

When a material removal is carried out from only one side i.e. called ablation process and the removed material must necessarily be ejected from the same side as which the laser is incident. Figure 3 Shows laser ablation process.

In both cases, the removed material is ejected primarily through the kerf which has been cut by laser beam and which trails along behind the laser beam as it is moved along the tool path. The material removal process involves both thermal and chemical processes, depending upon how the laser radiation interacts with the substrate. At longer wavelengths, the photon energy is insufficient to provide anything more than a simple heating of the substrate. At sufficiently high intensities, however, the heating can be concentrated enough to first melt the substrate material within a localized zone, and then vaporize it in those areas where the laser intensity and subsequent heating is higher. Then the substrate material is transition to the gas phase, although the vaporized material is often subsequently ionized by the laser radiation, leading to a plasma and plume that can have the effect of occluding the incident beam.

It is customary to identify three zones around the incident beam:

1. The heat-affected zone or HAZ

2. The melt zone

3. The vaporization zone.

Some materials can pass directly from the solid phase to vapour phase by sublimation, and thus melt zone is absent. Both melting followed by vaporization or direct sublimation that is purely thermal ablation processes. At shorter wavelengths, the photon energy may reach the level of the chemical bond strength of the substrate. Laser radiation may then break those chemical bonds through direct photon absorption, leading to volatilisation of the substrate into simpler compounds.

The investigators have [15] worked on short laser which are used for machining. In this process the photon energy is lost to chemical bond scission, the heating effects of the beam are greatly reduced, and this region is sometimes referred to as "cold laser machining," or photochemical ablation. This greatly reduces the transient thermal stresses that occur as part of thermal ablation, and thus result shows less bowing, warping, and delamination of the substrate, as well as fewer edge melting effects which degrade feature accuracy. Since the peak temperature rise is greatly reduced, conductive heat flow away from the irradiation area is also reduced, and better dimensional control of the micro machined structure is obtained. There has been a general trend toward using shorter wavelength lasers for micromachining over the past two decades of development. Currently, UV lasers in the range of 350 to $250 \mathrm{~nm}$ which are used in industrial market because of cold laser machining.

\section{Lasers for Post-processing (Laser Micromachining)}

There are different types of lasers are available in market for material processing. The researchers [16-18] have worked on lasers and discussed that by far the most common laser used for industrial processing is the carbon dioxide $\left(\mathrm{CO}_{2}\right)$ gas laser. This popularity comes from its unique combination of high average power, high efficiency, and rugged construction. $\mathrm{CO}_{2}$ lasers are used extensively for marking, engraving, drilling, cutting, 
welding, annealing, and heat treating an enormous variety of industrial materials. For micromachining applications, the long wavelength translates into a fairly large spot diameter of $\sim 50-150 \mu \mathrm{m}$ with a corresponding kerf width.

The most common solid-state laser used in the industry is the neodymium-doped yttrium aluminium-garnet, or Nd:YAG [19, 20]. For micromachining purposes there are four types of Nd:YAG lasers are used which gives different wavelength output which are $1064 \mathrm{~nm}, 532 \mathrm{~nm}$ (Green output), $355 \mathrm{~nm}$ (near ultraviolet-UVA band) and $266 \mathrm{~nm}$ (deep ultraviolet- UVC band).

Copper vapour lasers have also proven their use in high accuracy micromachining [21, 22]. Copper vapour lasers also have excellent beam quality and can usually produce a diffraction-limited spot on the substrate with only simple external beam steering optics. The disadvantage of copper vapor lasers is that they tend to have a shorter service life and require more maintenance than Nd: YAG lasers

Excimer lasers have also found wide use in materials processing applications [23]. Commonly used excimer lasers are the $\mathrm{XeF}$ which emits at $351 \mathrm{~nm}$, the $\mathrm{KrF}$ which emits at $249 \mathrm{~nm}$, the ArF which emits at $193 \mathrm{~nm}$, and the diatomic F2 which emits at $157 \mathrm{~nm}$. Like other laser systems this types of lasers are used in materials processing as per application.

The researchers [24] told us, at higher beam intensities laser can be used for surface ablation of materials and due to the short wavelength and short pulse width, laser typically produce clean, crisp features in metals, ceramics, glasses, polymers, and composites making them adaptable for numerous micromachining applications.

\section{Conclusion}

In this work, the literature related to various surface finish techniques has been reviewed. It has been found that there are various methods to improve surface finish of parts manufactured by Additive manufacturing. The surface finish can be improved by selecting suitable method as per the requirement of surface finish. The study of various works indicates that systematic implementation of post processing technique can improve the $R_{\mathrm{a}}$ value of parts. Most authors have put in efforts in designing the processes for post processing operations. In doing so, many assumptions such as the Abrasive size, feed rate in HCM, concentration of chemical, flow rate of abrasives, Laser power were assumed.

From this survey it is found that the surface finish can also be improved by using some post processing techniques. Out of post processing techniques, on-going research focused on chemical treatment on polymer and metal printed parts and Laser micro machining on polymer, metal and ceramic.

Acknowledgment This paper is a revised and expanded version of the article entitled, "Post processing methods used to improve surface finish of products which are manufactured by Additive Manufacturing (AM) technologies-A review" was presented in "International Conference on Additive Manufacturing and 3D Printing" held at Chennai, India during February 6-7, 2015.

\section{References}

1. K.V. Wong, A. Hernandez, A review of additive manufacturing. ISRN Mech. Eng. (2012). doi:10.5402/2012/208760

2. Harris R. Additive manufacturing research group, School of Mechanical and Manufacturing Engineering, Wolfson Building, Loughborough University, Loughborough, UK. http://www.lboro. ac.uk/research/amrg/about/the 7categoriesofadditivemanufacturing/

3. R.I. Campbell, M. Martorelli, H.S. Lee, Surface roughness visualization for rapid prototyping models. Comput. Aided Des. 34, 717-725 (2002)

4. Spencer JD, Cobb RC, Dickens PM. Vibratory finishing of stereolithography parts, Department of Manufacturing Engineering and Operations Management, University of Nottingham, UK. http://sffsymposium.engr.utexas.edu/Manuscripts/1993/1993-03Spencer.pdf

5. M. Schmid, C. Simon, G.N. Levy, Finishing of SLS-parts for rapid manufacturing (RM): a comprehensive approach. http:// utwired.engr.utexas.edu/lff/symposium/proceedingsArchive/pubs/ Manuscripts/2009/2009-01-Schmid.pdf

6. P.M. Pandey, N.V. Reddy, S.G. Dhande, Improvement of surface finish by staircase machining in fused deposition modeling. J. Mater. Process. Technol. 132, 323-331 (2003)

7. L.M. Galantucci, F. Lavecchia, G. Percoco, Experimental study aiming to enhance the surface finish of fused deposition modeled parts. CIRP Ann. Manufact. Technol. 58, 189-192 (2009). doi: 10.1016/j.cirp.2009.03.071

8. G. Percoco, F. Lavecchia, L.M. Galantucci, Compressive properties of FDM rapid prototypes treated with a low cost chemical finishing. Res. J. Appl. Sci. Eng. Technol. 4(19): 3838-3842 (2012), ISSN: 2040-7467, (C) Maxwell Scientific Organization, 2012

9. B. Duleba, F. Greškovič, J.W. Sikora, Materials and finishing method of DMLS manufactured parts. http://www.sjf.tuke.sk/ transferinovacii/pages/archiv/transfer/21-2011/pdf/143-148.pdf

10. Chil-Chyuan Kuo, Su Sheng-Jie, A simple method for improving surface quality of rapid prototyping. Indian J. Eng. Mater. Sci. 20, 465-470 (2013)

11. J.A. Ramos, J. Murphy, K. Wood, D.L. Bourell, J.J. Beaman, Surface roughness enhancement of indirect-SLS metal parts by laser surface polishing. http://www.sutd.edu.sg/cmsresource/idc/ papers/2001-_Surface_roughness_enhancement_of_indirect-SLS_ metal_parts_by_laser_surface_polishing.pdf

12. A. Lamikiz, J.A. Sanchez, L.N.L. Lacalle, J.L. Arana, Laser polishing of parts built up by selective laser sintering. Int. J. Mach. Tools Manuf 47, 2040-2050 (2007). doi: 10.1016/j.ijmachtools.2007.01.013

13. J.C. Ion, Laser processing of engineering materials, (Elsevier Butterworth-Heinemann, Oxford, UK, Burlington, Massachusetts, 2005), ISBN:0-7506-6079-1

14. D. Schuöcker, High power lasers in production engineering. (Imperial College Press, World Scientific, London, Singapore, 1999), ISBN:981-02-3039-7 
15. K.C. Yung, S.M. Mei, T.M Yue, A study of the heat-affected zone in the UV YAG laser drilling of GFRP materials. J. Mat. Proc. Tech. 122, 278-285, (2002) ISSN: 0924-0136

16. P.G. Berrie, F.N. Birkett, The drilling and cutting of polymethyl methacrylate (Perspex) by $\mathrm{CO} 2$ laser. Opt. Lasers Eng. 1(2):107-129 (1980), ISSN:0143- 8166

17. K.C.A. Crane, J.R. Brown, Laser-induced ablation of fibre/epoxy composites. J. Phys. D: Appl. Phys. 14(1)2:2341-2349 (1981) ISSN:0022-3727

18. K.C.A. Crane, Steady-state ablation of aluminium alloys by a CO2 laser. J. Phys. D: Appl. Phys. 15(10):2093-2098 (1982), ISSN:0022-3727

19. P.A. Atanasov, E.D Eugenieva, N.N. Nedialkov, Laser drilling of silicon nitride and alumina ceramics: a numerical and experimental study. J. Appl. Phys. 89(4):2013-2016 (2001) ISSN:00218979
20. L. Tunna, A. Kearns, W. O’Neill, C.J. Sutcliffe, Micromachining of copper using Nd:YAG laser radiation at 1064, 532, and $355 \mathrm{~nm}$ wavelengths. Opt. Laser Tech. 33(3):135-143 (2001), ISSN:0030-3992

21. M.R.H. Knowles, Micro-ablation with high power pulsed copper vapor lasers. Opt. Exp. 7(2):50-55 (2000), ISSN:1094-4087

22. J.S Lash, R.M. Gilgenbach, Copper vapor laser drilling of copper, iron, and titanium foils in atmospheric pressure air and argon. Rev. Sci. Inst. 64(11):3308-3313 (1993), ISSN:0034-6748

23. K.J. Kuhn, Laser engineering, (Prentice Hall, Upper Saddle River, 1998) ISBN:0-02-366921-7

24. M.C. Gower, Industrial applications of laser micromachining. Opt. Exp. 7(2):56-67 (2000), ISSN:1094-4087 